from the midshipmen's berth, and sent him into the gun-room, to mess with the lieutenants, surgeon, aud purser; but no more severe punishment than a reprimand was inflicted on those who, having forfeited all claim to the character of gentlemen, ought to have been instantly expelled the service.

Such, Mr. Editor, are a few of the very honourable and bighly flattering inducements held out to the future aspirants for the rank and dignity of assistant-surgeon in H. MI. naval service; and, I ask, should not all such who hereafter enter the nary with their eyes open, and a full conviction of the indignities they nust submit to--should not such b: held up to the deserved contempt and obloquy of the whole profession? Yes; and what is more, every assistant-suryeon in the service, who has any respect for himself or his profession, will look on them as his bitterest enemies.

Naples, August, 1819.

Medrcos.

\section{THE FUNDS OF THE ROYAL COLLEGE OF SURGEONS.}

To the Editor of The LaNCET.

Sin,-The greatest abuse in the council of the College of Surgeons is in the mode in which the examiners are paid, as will be shown by the following statement:-

In The LATCET of the 19 th inst., you say that out of twelve gentlemen examined at the last meeting of the court of examiners, eight were rejected.

Now the profession will scarcely believe the manner in which the money received for the diplomas is expended.

'Thus the eight rejected candidates pay nothing. The four successful pay twenty guineas each, making altogether eighty guineas. Of these, four guineas are paid for diploma stamps, sixty guineas to examiners, and sixteen guineas only go to the funds of the college. And provided there be seven examiners present to form a court, they receive the sum which would be divided between the ten.

- I trust, Sir, for the salie of the profession, you will insert this letter in your next number.

Jan. 21, 1850.

I am, Sir, your obedient servant

* * We cannot vouch for the accuracy of the statement contained in this note. If the allegations made be correct, our correspondent might have noticed the eight rejections out of twelve applications in a commendatory spirit. As the refusal of the diploma is also a refusal to receive money, certainly it does not appear, by the results of the last examination, that the examiners were so far unmindful of their duty as to prefer their own interests to those of the profession and the public. At the same time we feel bound to observe, that the principle of paying the examiners according to the number of the diplomas granted, is, in our opinion, radically objectionable.-Ev. L.

\section{CAPSICUM A CURE FOR CHILBLAINS AND TOOTHACH.}

To the Editor of THE LANCET.

SIr,-At this season, few diseases are so general as chilblains, and the plans that are generally employed for their removal are seldom attended with more than very slight advantage to the sufferers.

It is a disease that attacks, most generally, females, and delicate children, and those of a languid circulation. The very numerous and various medicines which have been from time to time employed, prove very clearly that no very effective or successful plan of treatment has hitherto been found. Such is the present state of treatment both of chilblains and toothache.

My plan of treatment is, simply, to saturate a piece of sponge, or flannel, with the concentrated tincture of capsicum, and to rub well over the seat of the chilblains, until such time as a strong tingling and clectrical fecling is produced.

This medicine possesses an extraordinary power in removing congestion, by its action upon the nerves and circulation.

This application ought to be continued daily until the disease is removed.

Relief will be expericnced on the very first application, and, frequently, there will be a total removal of the disease after the second or third. This, of course, depends upon the severity of the case. This embrocation, when rubbed, never produces excoriation, if the skin is not broken.
The manner of using it for toothach, is by putting a drop or two of the tincture on cotton, and applying it to the part affected; the relief will be immediate. The following is the formulæ: - Concentrated tincture of capsicum : cayenne pepper, four ounces; rectified spirit of wine, twelve ounces. Macerate, daily, for a week, and strain. (It may also be made with advantage by displacement.)

I remain, Sir, your obedient servant,

Manchester-square, January, is50. A. TCRsBtLL, MI.D.

\section{THE GENTEEL OUT-PATIENT ABUSE AT HOSPITALS.}

To the Editor of The LANCET.

SIk, - A subject of very considerable importance (the abuse of medical institutions by respectable persons) has, from time to time, been alluded to in your journal, but nothing at all definite or satisfactory has hitherto been deduced as the result. In order to prevent the remarks which I purpose submitting to the notice of your readers from extending beyond the liberal limits of the space in THE LANCET, which you so freely offer for the exposure of "professional grievances" I will at one proceed to the "evil" I have now before me, justly designated by yourself a "gigantic" one.

I have watched for some considerable period, and with much interest, the patients admitted to our numerous metropolitan hospitals and dispensaries, and can, in a great measure, corroborate the statement made by your correspondent, $\mathbf{M r}$. Hodgson, that the noble privileges they offer are to a vast extent abused by persons unquestionably beyond the sphere of those for whom their eleemosynary aid is intended.

It by no means unfrequently happens that, in our endeavours to avoid one extreme of anything to which our attention is divected, we are too apt to glide-imperceptibly, it may beinto the other: this I almost fear we shall do in this present matter, unless we have it clearly defined for what class or classes of persons hospitals and dispensaries are established. In alluding to charitable institutions in general, hospitals and dispensaries are generally mentioned together, and supposed to be established with the self-same oljject in view-the relief of the afflicted poor-different only in the degree of their usefulness. I hesitate to acknowledge the correctness of this supposition-nay, I venture to state my belief that it is erroneous, for the advantages offered by hospitals are so varied in character and so vast in extent, that they embrace in the wide field of their usefulness a much larger class than can claim the aid of dispensaries. The latter, I conceive, are established, not so much for those who are, somewhat tautologically, called "the afflicted and necessitous poor", as for those whom I may perhaps term "the aflicted and necessitous respectable," -those persons I mean, who, having once seen " better days," are now maintaining a laudable struggle between respectability and pauperisin, and who would inevitably be claimed as the victims of the latter when sickness comes upon them, unless dispensaries stepped in to assist them in their unequal and terrible contest. The poor-_" paupers," so to speak-are already provided for by the parishes to which they severally belong, and when they are admitted as hospital or dispensary out-patients, they are receiving professional aid at a distance, which can be as efficiently rendered by the surgeon appointed to attend them by the parish in which they reside. Upon making the inquiry of two patients of a dispensary why they seek its aid, one will perhaps very coolly tell you that he does not like the "parish doctor;" and the other, that he has paid for medical advice until he can do so no longer. The former, $I$ apprehend, has no claim upon the dispensary, while the latter has every claim. It is, further, of not unfrequent occurrence for the former to have the "parish surgeon" attending upon him for the benefit of his orders for relief, and the "dispensary doctor" for the benefit of his physic stuff To hospital in-patients the above remarks do not apply, as aid is thereby furnished which could not be procured at the residence of the patient. Severe dislocations and fractures, for instance,-cases requiring capital operations, such as hernia, cannot be properly attended to in the wretched cellars and garrets where unfortunate "paupers" are supposed to live, but in reality linger out their existence and die! I have already stated that I agree with MIr. Hodgson that hospitals and other institutions of the kind are much abused, but $I$ think not to the extent he imagines. It is difficult of belief, for instance, that one half the ophthalmic infirmary patients can afford a fee to the surgeon; and though some may adopt the expedient of disguise, there are, on the other hand, many, 